\title{
The relationship of gestational weight gain and development of gestational diabetes mellitus
}

\author{
B G C S M Banagala ${ }^{a}$, M Karunarathne ${ }^{b}$
}

\begin{abstract}
Objective: To assess the effect of gestational weight gain in women developing gestational diabetes mellitus (GDM).

Methods: In this retrospective case control study, singleton mothers with GDM $(n=51)$ were compared with a control group ( $n=153$ ) matched for age ( \pm 2 years), parity, booking visit BMI $\left( \pm 2 \mathrm{~kg} / \mathrm{m}^{2}\right)$. They were reviewed at delivery to identify sociodemographic risk factors and treatment modality if they were found to have GDM. Maternal weight at booking visit, at the end of 1 st trimester and at the time of glucose tolerance testing was extracted from maternity records. Total gestational weight gain, and rate of weight gain per week during $1^{\text {st }}$ and $2^{\text {nd }}$ trimesters were the primary outcome data.

Results: Having a 1st degree relative with diabetes had a significant association for development of GDM. No significant difference was observed in total weight gain or $2^{\text {nd }}$ trimester weight gain between case and controls. However, weight gain during $1^{\text {st }}$ trimester was significantly higher among mothers diagnosed with GDM when compared with controls. This difference was most significant among normal and overweight BMI categories. Out of the GDM group, although the mean rate of weight gain was higher in the pharmacotherapy sub group, there was no statistical significance compared with the group who was only on Medical Nutrition Therapy.

Conclusions and recommendations: Gestational weight gain during first trimester was significantly higher among patients with GDM who were in the normal and overweight BMI categories compared to normal glucose tolerant individuals. Mothers with excessive 1st trimester weight gain should be carefully followed up for development of GDM.
\end{abstract}

Key words: gestational weight gain, risk factors, gestational diabetes mellitus

Sri Lanka Journal of Obstetrics and Gynaecology 2019; 41: 104-110

DOI: http://doi.org/10.4038/sljog.v41i4.7905

a Consultant Obstetrician \& Gynaecologist, Base Hospital Balangoda, Sri Lanka.

b Consultant Obstetrician \& Gynaecologist, Sri Jayewardenepura General Hospital, Sri Lanka.

Correspondence: CSMB, e-mail: <chin.maithri@gmail.com>

Received 10 ${ }^{\text {th }}$ November 2019 and revised version accepted 20th November 2019.

(D) https://orcid.org/0000-0003-1872-3648

Competing interest: The authors report no conflict of interest

This is an open-access article distributed under the terms of the Creative Commons Attribution 4.0 International License, which permits unrestricted use, distribution and reproduction in any medium provided the original author and source are credited. 


\section{Introduction}

Pregnancy is considered as a state of insulin resistance, and women who cannot increase their insulin production to overcome this resistance will develop Gestational Diabetes Mellitus (GDM) ${ }^{1}$. GDM is defined as any level of glucose intolerance, which is first detected during pregnancy.

It is an important cause for perinatal morbidity and mortality globally ${ }^{2}$. It is also known to cause long term complications to both the mother and the fetus which results in high cost for healthcare and poses a significant economic burden ${ }^{3}$, hence early detection and prompt treatment of GDM is a vital component of successful management to reduce its complications. Understanding the potential associations which carries high risk for GDM is important when screening for the condition. Previous history of GDM, advanced maternal age, increased body mass index (BMI), family history of diabetes, specific ethnic groups are well known risk factors for developing $\mathrm{GDM}^{4}$.

Both in pregnancy and non-pregnant adults obesity is associated with an increased insulin resistance and that is due to abnormal regulation of cytokine production by the adipose tissue ${ }^{5}$.

Excessive weight gained during pregnancy can affect current pregnancy and future health of a woman and her infant such as pregnancy induced hypertension (PIH), macrosomia, primary cesarean delivery due to dysfunctional labor and cephalo-pelvic disproportion ${ }^{6,10}$.

During the past two decades a rising trend in GDM was observed in Sri Lanka ${ }^{11,12}$. Hypothetically excessive gestational weight gain could be linked to development of GDM by increasing insulin resistance. Therefore, maintaining acceptable weight gain during early pregnancy may have a protective effect against development of GDM.

This retrospective case control study aims to assess this relationship of gestational weight gain and risk of development of gestational diabetes.

\section{Methods and materials}

A case controlled study was conducted during August 2014 to January 2015 in Sri Jayewardenepura General Hospital, Nugegoda, Sri Lanka, to assess the effect of gestational weight gain and socio-demographic factors on development of gestational diabetes mellitus and its effect on treatment modality.
All singleton mothers who were admitted for confinement in the unit during the period were invited to participate in the study. After obtaining informed written consent, mothers with a singleton pregnancy and who have attended and followed up in the hospital antenatal clinic with weight measurement and oral glucose tolerance testing (OGTT) at 24-28 weeks of gestation were included into the study. Having previous history of type 1 , type 2 or gestational diabetes mellitus, booking after 10 weeks, multiple pregnancies, history of other metabolic disorders or treated with drugs which can interfere with glucose homeostasis (e.g. thyroid diseases, Cushing's, steroid treatment), uncertainty of the period of gestation, first trimester and onward weight values are not available and OGTT done at a gestation other than 24-28 weeks were the exclusion criteria.

Using the Open-Epi ${ }^{13}$; a web-based epidemiological and statistical calculator, a sample size to achieve a significant result was calculated. Parameters for sample size estimation were drawn from Gibson et al $2012^{9}$ study of 'Maternal weight gain in women who develops GDM'. According to the calculations around 50 mothers with GDM and around 150 mothers without GDM as control group were needed.

Data was obtained through an interviewer administered questionnaire and a data extraction sheet. Gestation at the first prenatal visit, weight and height at the first prenatal visit, subsequent weights at the end of first trimester and second trimesters, results of the glucose tolerance test at 24-28 weeks were extracted through the pregnancy record sheet. Socio-demographic details, family history of diabetes, treatment modality for diabetes were obtained through an interviewer administered questionnaire. Corrected expected date of delivery by first trimester ultrasound scan was taken to calculate the gestational age if there were discrepancies.

BMI calculated at the booking visit was taken as an approximate to the pre pregnancy BMI. They were categorised as underweight $\left(<18.5 \mathrm{~kg} / \mathrm{m}^{2}\right)$, normal $\left(18.5-24.9 \mathrm{~kg} / \mathrm{m}^{2}\right)$, overweight $\left(25.0-29.9 \mathrm{~kg} / \mathrm{m}^{2}\right)$ or obese $\left(\geq 30.0 \mathrm{~kg} / \mathrm{m}^{2}\right)$ according to this BMI ${ }^{17}$.

Net weight gain up to screening for GDM (maximum up to 28 weeks) and the rates of weight gain (kilograms per week) were calculated. The rate of gestational weight gain, per week was calculated by dividing the 
maternal weight difference between booking visit and at the time of glucose tolerance testing, by the weeks of gestation elapsed between these two points.

As per NICE guidelines, GDM was diagnosed as fasting blood sugar more than $7.0 \mathrm{mmol} / \mathrm{L}(126 \mathrm{mg} / \mathrm{dL})$ or $2 \mathrm{hr}$ value above $7.8 \mathrm{mmol} / \mathrm{L}(140 \mathrm{mg} / \mathrm{dL})$ at gestational age between $24-28$ weeks $^{18}$.

Each patient with GDM was matched with three women who had normal glucose tolerance testing. Mothers without GDM were screened at confinement with a postprandial blood sugar test (less than $140 \mathrm{mg} / \mathrm{dl}$ was considered as normal). If they found to have late onset GDM they were excluded from the study.

Assignment was achieved using one-to-one assignment for the first three matching women delivering at this institution and cases were matched to controls for known confounders namely age ( \pm 2 years), booking visit BMI $\left( \pm 2 \mathrm{~kg} / \mathrm{m}^{2}\right)$, and parity. The first three controls matching for each case were selected. If a control participant did not meet inclusion criteria, the next eligible control was selected. When a control subject selected, that patient was omitted from future selections to ensure that the same control patient will not be used more than once.

\section{Outcome measures}

Mean total weight gain, rate of total weight gain, rate of weight gain up to 12 weeks, rate of $2^{\text {nd }}$ trimester weight gain was then compared between GDM group and controls according to each BMI category. From the GDM group, further information was collected on their treatment modality and categorized into patients requiring medical nutrition therapy alone or patients requiring additional pharmacological therapy.

\section{Statistical analysis}

For continuous variables, data were analyzed using both parametric and non parametric tests with Student t test, Mann-Whitney U test and Kruskal-Wallis test. Chi square test was used to estimate the significance in differences between two categorical variables. Results were interpreted at the $95 \%$ confidence interval with a significance level of $P<0.05$.

Ethical approval was obtained by the Ethical Review Committee of Sri Lanka Medical Association (SLMA).

\section{Results}

During the study period 73 women were identified who was diagnosed with GDM for the first time. Out of that 22 were excluded from the study due to presence of exclusion criteria. Women without GDM were identified as controls who met the inclusion criteria and matched for age, parity and first trimester BMI to identify the control group ( $\mathrm{n}=153)$. The characteristics of cases with GDM and the control group are presented in table 1.

Presence of 1st degree family history of diabetes was found to be significantly associated with development of GDM ( $\mathrm{p}=0.033)$. Race, monthly family income, education level was not significantly associated with development of GDM. Significance of marital status could not be calculated due to presence of very low numbers in unmarried and widow categories.

Different weight gain patterns among cases and controls, which was the primary outcome measure during the study are presented in table 2 .

No significant differences were found in total weight gain, total rate of weight gain or $2^{\text {nd }}$ trimester weight gain between control subjects and patients with GDM. However, a significant association was observed in rate of weight gain during 1st trimester between the two groups $(0.027 \mathrm{~kg} /$ week compared with $0.166 \mathrm{~kg} /$ week, $P=<0.001)$.

In order to observe these differences according to the BMI categories of individuals, weight gain was compared according to their booking visit BMI groups. Lowest total weight gain was seen among the controls and GDM participants who were obese. There was no statistically significant difference in total weight gain, $2^{\text {nd }}$ trimester weight gain between controls and cases in any of the BMI categories.

However when weight gain only up to 12 weeks compared within different BMI categories, rate of first trimester weight gain was significantly more among mothers with GDM who were in normal or overweight BMI categories.

To examine whether there was a significance between gestational weight gain and severity of GDM, total rate of weight gain was compared for mothers with GDM according to the two treatment strategies (medical nutrition therapy - MNT and pharmacotherapy). Although the mean rate of weight gain was higher in mother who needed pharmacotherapy (metformin or insulin) there was no statistical significance between the two groups $(P=0.750)$. 
Table 1. Socio-demographic data of the cases and controls

\begin{tabular}{|c|c|c|c|c|}
\hline & & $\begin{array}{l}\text { Gestational } \\
\text { Diabetes Mellitus } \\
(n=51)\end{array}$ & $\begin{array}{l}\text { Control } \\
(n=53)\end{array}$ & $\boldsymbol{P}$ \\
\hline Age at delivery & Mean age & $31.72( \pm 4.2)$ & $31.58( \pm 2.8)$ & 0.857 \\
\hline \multirow[t]{4}{*}{ Parity } & 0 & $14(27.5)$ & 41 (26.8) & 0.900 \\
\hline & 1 & $32(62.7)$ & 94 (61.4) & \\
\hline & 2 & $4(7.8)$ & $15(9.8)$ & \\
\hline & 3 or more & $1(2.0)$ & $3(2.0)$ & \\
\hline \multicolumn{5}{|l|}{ Mean Body Mass } \\
\hline $\begin{array}{l}\text { Index }\left(\mathrm{kg} / \mathrm{m}^{2}\right) \text { at } \\
\text { booking visit }\end{array}$ & Mean BMI & $26.16( \pm 0.51)$ & $25.86( \pm 0.33)$ & 0.647 \\
\hline \multirow{4}{*}{$\begin{array}{l}\text { BMI }\left(\mathrm{kg} / \mathrm{m}^{2}\right) \text { at } \\
\text { booking visit } \\
\text { (BMI category) }\end{array}$} & $<18.49$ & $0(0.0)$ & $0(0)$ & \\
\hline & $18.50-24.99$ & $21(41.2)$ & $58(37.9)$ & \\
\hline & 25.00-29.99 & $24(47.1)$ & 76 (49.7) & \\
\hline & $>30.00$ & $6(11.8)$ & $19(12.4)$ & \\
\hline \multirow[t]{3}{*}{ Marital status } & Single & $0(0.0)$ & $1(0.7)$ & N/A \\
\hline & Married & $50(98.0)$ & 152 (99.3) & \\
\hline & Widow/Separated & $1(2.0)$ & $0(0.0)$ & \\
\hline \multirow[t]{4}{*}{ Educational attainment } & None & $0(0.0)$ & $1(0.7)$ & 0.254 \\
\hline & Primary & 7 (13.7) & $13(8.5)$ & \\
\hline & Secondary & $33(64.7)$ & $127(83.0)$ & \\
\hline & Tertiary & $11(21.6)$ & $12(7.8)$ & \\
\hline \multirow[t]{4}{*}{ Monthly income } & $<10000$ & $0(0.0)$ & $0(0.0)$ & 0.890 \\
\hline & $10000-50000$ & $26(51.0)$ & $80(52.3)$ & \\
\hline & $50000-100000$ & $22(43.1)$ & $62(40.5)$ & \\
\hline & $>100000$ & $3(5.9)$ & $11(7.2)$ & \\
\hline \multirow[t]{4}{*}{ Family history of diabetes } & $1^{\text {st }}$ degree relative & $19(37.2)$ & $34(22.2)$ & 0.033 \\
\hline & $2^{\text {nd }}$ degree relative & $3(5.8)$ & $9(5.9)$ & \\
\hline & No & 27 (52.9) & 108 (70.6) & \\
\hline & Do not know & $2(3.9)$ & $2(1.3)$ & \\
\hline
\end{tabular}


Table 2. Comparison of weight gain between cases with GDM and controls

\begin{tabular}{|llll|}
\hline & Control (n=153) & GDM (n=51) & $P$ \\
\hline Total weight gain $(\mathrm{kg})$ & $4.595( \pm 0.248)$ & $4.112( \pm 0.400)$ & 0.332 \\
\hline Rate of total weight gain $(\mathrm{kg} /$ week $)$ & $0.299( \pm 0.021)$ & $0.235( \pm 0.021)$ & 0.099 \\
\hline Weight gain up to 12 weeks (kg/week) & $0.027( \pm 0.015)$ & $0.166( \pm 0.034)$ & $<0.001$ \\
\hline $2^{\text {nd }}$ trimester weight gain $(\mathrm{kg} /$ week $)$ & $0.397( \pm 0.026)$ & $0.313( \pm 0.031)$ & 0.092 \\
\hline
\end{tabular}

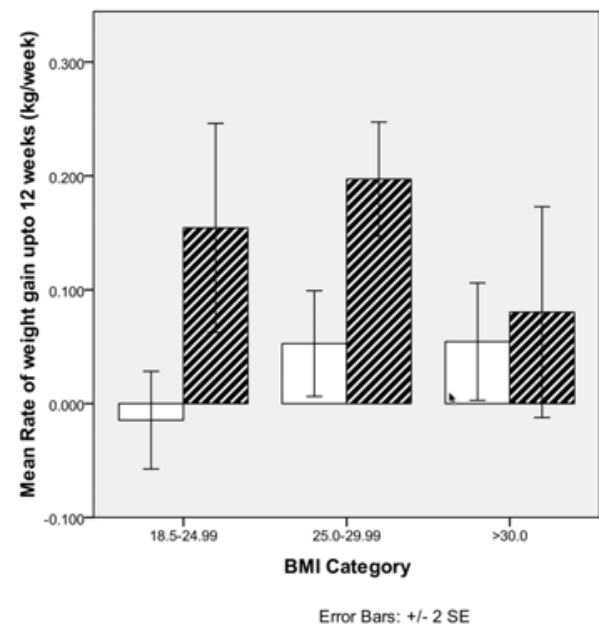

Figure 1. First trimester weight gain in cases with GDM and controls according to there pre pregnancy BMI

\section{Discussion}

The study demonstrated that a higher weight gain in $1^{\text {st }}$ trimester was significantly associated with subsequent risk of developing GDM. However, it failed to identify a significant association in total or $2^{\text {nd }}$ trimester weight gain for development of GDM. This is comparable to the findings of two studies conducted in United States of America ${ }^{8,9}$. Total body water accumulation is the main determinant in gestational weight gain though the fat deposition is also partly responsible ${ }^{15}$. It has been found that there is a variation in the level of fat mass accumulation in women with different BMI strata ${ }^{16}$. This understanding of the

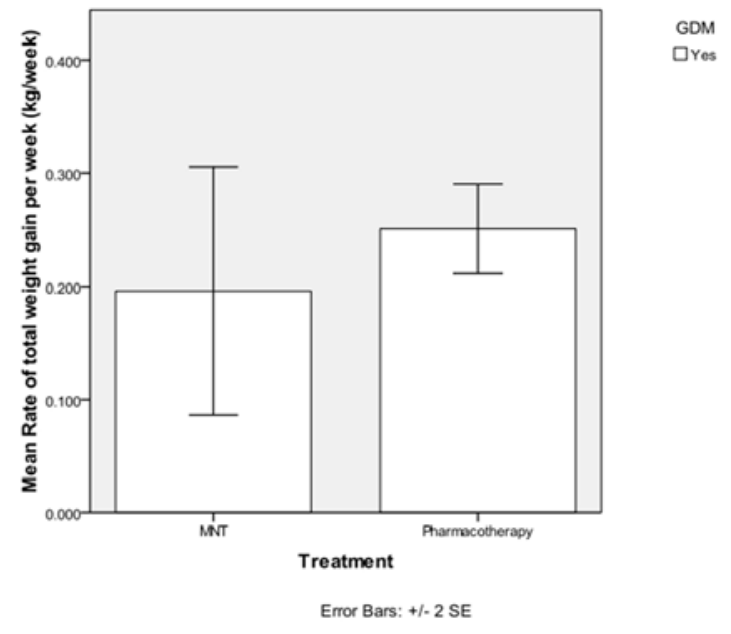

Figure 2. Comparison of rate of weight gain observed in case with GDM according to their treatment modality

physiology behind weight gain may help us explain the study findings.

Rapid early gestational weight gain may lead to exhaustion of $\beta$ cell and "push the high risk group over the edge" towards developing GDM. It has been shown that early gestational weight gain is mainly contributed by fat mass increments ${ }^{14}$. These crucial early changes may continue to control over development of GDM irrespective of the subsequent changes.

When analysed by booking visit BMI categories this difference was significant only among normal and 
overweight groups. In contrast in a case controlled study done in $\mathrm{Ohio}^{9}$, weight gain was significantly higher only in overweight and obese patients who developed GDM.

Reasons contributing for this difference may be, rate of weight gain is slowest among obese women and hence failing to reach a statistical significance. Secondly, although BMI more than $23 \mathrm{~kg} / \mathrm{m}^{2}$ is considered overweight for Asians ${ }^{19}$, inclusion of BMI group 23$25 \mathrm{~kg} / \mathrm{m}^{2}$ to normal BMI category may have contributed to achieving significance in normal BMI group.

These findings were not proven consistently during studies among Asian populations ${ }^{6,7,10}$.

Although the rate of weight gain was found to be higher in patients with GDM who were on pharmacotherapy in comparison to patients on MNT only, this association was not statistically significant. Previous studies have demonstrated an association with gestational weight gain and the severity of GDM determined by the type of treatment offered ${ }^{9}$. Therefore, even one goes on and develops GDM, severity of the condition may become less if she had an acceptable weight gain up to that point.

\section{Conclusion and recommendation}

Gestational weight gain during first trimester was significantly higher among patients with GDM who were in the normal and overweight BMI categories compared to normal glucose tolerant individuals.

Since higher, early gestational weight gain is associated with a higher risk of developing GDM, health care providers may need to be more vigilant on detecting GDM in them. Awareness needs to be created among public and health care workers, that excessive early gestational weight gain might be a modifiable risk factor for GDM.

Whether optimizing BMI and reduction of excessive weight gain during this period will work as a preventive strategy needs further assessment by interventional studies. A proper pre pregnancy counselling program combined with early pregnancy advice to reduce weight gain may help in achieving this task and since most women will book at primary care clinics around 6-10 weeks this appears to be feasible.

Further research with larger sample size is recommended in order to study different outcomes of excessive gestational weight gain.

\section{References}

1. Kühl C. Insulin secretion and insulin resistance in pregnancy and GDM: implications for diagnosis and management. Diabetes. 1991; 40(Supplement 2): $18-24$.

2. Persson B, Hanson U. Neonatal morbidities in gestational diabetes mellitus. Diabetes care 1998; 21: B79.

3. Buchanan TA, Kjos SL. Gestational diabetes: risk or myth? Journal of Clinical Endocrinology and Metabolism 1999; 84(6): 1854-7.

4. Scott DA, Loveman E, McIntyre L, Waugh N. Screening for gestational diabetes: a systematic review and economic evaluation. Health Technology Assessment. 2002; 6(11).

5. Hotamisligil GS, Arner P, Caro JF, Atkinson RL, Spiegelman BM. Increased adipose tissue expression of tumor necrosis factor-alpha in human obesity and insulin resistance. Journal of Clinical Investigation 1995; 95(5): 2409.

6. Hung TH, Chen SF, Hsu JJ. Gestational weight gain and risks for adverse perinatal outcomes: A retrospective cohort study based on the 2009 Institute of Medicine guidelines. Taiwanese Journal of Obstetrics and Gynecology 2015; 54(4): 421-5.

7. Li C, Liu Y, Zhang W. Joint and Independent Associations of Gestational Weight Gain and PrePregnancy Body Mass Index with Outcomes of Pregnancy in Chinese Women: A Retrospective Cohort Study. PloS one. 2015; 10(8): e0136850.

8. Hedderson MM, Gunderson EP, Ferrara A. Gestational weight gain and risk of gestational diabetes mellitus. Obstetrics and Gynecology 2010; 115(3): 597.

9. Gibson KS, Waters TP, Catalano PM. Maternal weight gain in women who develop gestational diabetes mellitus. Obstetrics \& Gynecology. 2012; 119(3): 560-5.

10. Cho EH, Hur J, Lee KJ. Early Gestational Weight Gain Rate and Adverse Pregnancy Outcomes in Korean Women. PloS one 2015; 10(10): e0140376.

11. Siribaddana SHRD, Rajapakse D. The prevalence of gestational diabetes in Lankan antenatal clinic. Ceylon Medical Journal 1998; 1998(43): 88-91.

12. Dahanayaka N, Agampodi S, Ranasinghe O, Jayaweera P, Wickramasinghe W, Adhikari A, 
et al. Inadequacy of the risk factor based approach to detect gestational diabetes mellitus. Ceylon Medical Journal. 2012; 57(1).

13. Sullivan KM, Dean A, Soe MM. Open Epi: a webbased epidemiologic and statistical calculator for public health. Public health reports. 2009: 471-4.

14. Hytten F, Chamberlain G. Clinical physiology in obstetrics: Blackwell Scientific Publications; 1980.

15. Butte NF, Ellis KJ, Wong WW, Hopkinson JM, Smith EB. Composition of gestational weight gain impacts maternal fat retention and infant birth weight. American Journal of Obstetrics and Gynecology. 2003; 189(5):1423-32.
16. Lederman SA, Paxton A, Heymsfield SB, Wang J, Pierson RN. Body fat and water changes during pregnancy in women with different body weight and weight gain. Obstetrics and Gynecology. 1997; 90(4, Part 1): 483-8.

17. http://www.euro.who.int/en/health-topics/diseaseprevention/nutrition/a-healthy-lifestyle/bodymass-index-bmi

18. NICE guidelines: Gestational diabetes: risk assessment, testing, diagnosis and management.

19. Using appropriate body mass index cut points for overweight and obesity among Asian Americans. Jane Jhi et al. NIH Public access, Published online 2014 Apr 13. 